\title{
(Sem) saber e (com) poder nos estudos organizacionais*
}

\section{(Without) knowledge and (with) power in organizational studies}

\author{
José Henrique de Faria ${ }^{1}$ \\ Francis Kanashiro Meneghetti ${ }^{2}$
}

\section{Resumo}

Bacon afirma que saber é poder. Tragtenberg contesta. Essa discussão, na contemporaneidade, faz-se mais importante do que se possa imaginar. Por isso, o objetivo central deste artigo é verificar as relações entre saber e poder, na atualidade, levando em consideração o papel da ciência e dos elementos imediatos a ela relacionados. Quanto aos objetivos específicos deste estudo, destacam-se:

- compreender o sentido da filosofia e da ciência e suas relações com a ideologia;

- verificar como o discurso da neutralidade axiológica da ciência se apresenta como mito da modernidade e como se dá a presença da "fé" na filosofia e na ciência, na contemporaneidade;

- refletir sobre a consolidação da ciência como força produtiva e/ou como mercadoria no atual sistema econômico;

- destacar a importância do complexo industrial militar como financiador de grande parte dos atuais estudos científicos;

- $\quad$ entender o processo de racionalização, avaliando a importância do pragmatismo e da burocracia universitária como afirmação da ciência na atualidade.

O texto conclui que tanto é possível a existência de saber como poder (Bacon) como a de não saber, mas com poder (Tragtenberg) para compreendermos a relação entre saber e poder.

Palavras-chave: estudos organizacionais; poder; saber; ciência; teoria crítica.

\begin{abstract}
Bacon claims that knowledge is power. Tragtenberg disagrees. This debate is now more important that can be imagined. Therefore, the main aim of this article is to examine the relationships between knowledge and power nowadays, taking into consideration the role of science and the elements immediately related to it. The most specific objectives of this study are: to understand the meaning of philosophy and science and their relationship with ideology; to examine how the discourse of the axiological neutrality of science is presented as a modern myth and how "faith" fits into philosophy and science nowadays; to reflect on the consolidation of science as a productive force and/or as a commodity in the current economic system; to highlight the importance of the military industrial complex as a financer of many current scientific studies; to understand the reasoning process, evaluating the importance of pragmatism and university bureaucracy as a statement of science nowadays. The text concludes that both knowledge as power is possible (Bacon) and the lack of knowledge, but with power (Tragtenberg) when it comes to understanding the relationship between knowledge and power.
\end{abstract}

Key words: organizational studies; power; knowledge; science; critical theory.

\footnotetext{
* Uma versão preliminar deste estudo foi apresentada no XXXIII Encontro da Anpad (Enanpad) 2008.

1 Pós-Doutorado em Labor Relations pel ILIR - University of Michigan e Doutorado em Administração pela Universidade de São Paulo- Faculdade de Economia, Administração e Contabilidade da Universidade de São Paulo - FEA/USP. Professor Titular do Programa de Mestrado Interdisciplinar em Organizações e Desenvolvimento da FAE Centro Universitário; Professor Titular Sênior do Programa de Pós Graduação em Educação - PPGE (Mestrado e Doutorado) da UFPR; Pesquisador PQ do CNPq; Líder do Grupo de Pesquisa Economia Política do Poder e Estudos Organizacionais. Endereço: Rua Itupava, 1.299 - Sala 103 - Hugo Lange - Curitiba- PR - Brasil - CEP: 80.040-000. E-mail: jhfaria@gmail.com.

2 Administrador (UFPR), Mestre em Administração pela Universidade Federal do Paraná -UFPR - e Doutor em Educação Universidade Federal do Paraná UFPR .Professor Titular do Programa de Mestrado e Doutorado em Administração da Universidade Positivo.Endereço: Rua Professor Rua Prof. Pedro Viriato Parigot de Souza, 5300 - $5^{\circ}$ andar - Prédio da Biblioteca da Universidade Positivo. Campo Comprido - Curitiba/Paraná - Brasil. CEP: $81280-330$ E-mail: fkmeneghetti@gmail.com
}

Artigo submetido em abril e aceito em junho de 2009 


\section{Introdução}

Marx afirma que a maneira como as coisas se apresentam não é a maneira como elas realmente são, uma vez que, se as coisas fossem como se apresentam, a ciência não existiria. Popper entende que, por ser necessariamente humana, a ciência é falível. Em ambas as informações, constata-se a necessidade de ir além do imediato e do aparente, além de apreender as relações sociais na produção da ciência, ponto central para a compreensão da forma do saber instituído. / Ambas as informações indicam a necessidade de ir além do imediato e do aparente. Além disso, mostram que apreender as relações sociais na produção da ciência é o ponto central para a compreensão da forma do saber instituído. Se, por um lado, de forma geral, as epistemologias de Marx e de Popper são divergentes, por outro, é inegável que ambos concebem a ciência como caminho para o domínio crescente do homem sobre a natureza. Assim, a relação entre ciência e poder é uma discussão constante, não só porque esteja intimamente relacionada à ideologia, mas também por estar associada à força produtiva, às condições materiais de existência, às relações de produção e assim por diante.

Portanto, o objetivo central deste artigo é verificar as relações entre saber e poder na atualidade, levando em consideração o papel da ciência e dos elementos imediatos a ela relacionados. Quanto aos objetivos específicos deste estudo, eles são:

compreender o sentido da filosofia e da ciência e suas relações com a ideologia;

verificar como o discurso da neutralidade axiológica da ciência se apresenta como mito da modernidade e como se dá a presença da "fé" na filosofia e na ciência, na contemporaneidade;

refletir sobre a consolidação da ciência como força produtiva e/ou como mercadoria no atual sistema econômico;

destacar a importância do complexo industrial militar como financiador de grande parte dos atuais estudos científicos; e

entender o processo de racionalização, avaliando a importância do pragmatismo e da burocracia universitária como afirmação da ciência na atualidade.

\section{Da fllosofia à clêncla como materialidade da Ideologia}

O que há de comum entre Marx e Popper? Quais são as semelhanças entre Rousseau e Hobbes? Entre os dois primeiros transparece a crença de que a ciência seja a forma mais "confiável" para a compreensão da realidade, ao mesmo tempo em que ambos demonstram "desconfiança" quanto à própria ciência simplesmente, porque está é feita pelos homens. A convergência entre Rousseau e Hobbes reside na importância da sociedade na constituição do indivíduo, mesmo que por vias diferentes. Enquanto o primeiro acredita que o homem nasce bom, mas que a sociedade o corrompe, o segundo acredita que o homem é o "lobo do homem" e que a sociedade acaba por regular as relações entre eles, possibilitando sua convivência social.

É fato que, apesar de divergências entre filósofos e também entre cientistas, desde o século XVI, a razão iluminista manifesta-se como consequência de uma nova organização socioeconômica. As relações entre os indivíduos e entre estes e a sociedade passam a se modificar em decorrência de novas formas de relações de produção.

Desde essa época, uma nova racionalidade passa a ser dominante, transformando cientificamente a relação do homem com o meio em que vive. Com a força dessa racionalidade científica, os indivíduos intensificam a separação entre homem e natureza, tornando-a mais evidente. A ciência vai se transformando, na medida em que vai produzindo transformações na realidade. Torna-se, dessa forma, força produtiva no capitalismo, por se apresentar justamente como o principal instrumento da separação entre o pensar e o agir, ou seja, entre trabalho intelectual e trabalho manual.

Mesmo a filosofia, na atualidade, é influenciada pela ciência moderna. Assim, 
a filosofia oficial serve à ciência que funciona dessa maneira. Ela deve, como uma espécie de taylorismo do espírito, ajudar a aperfeiçoar seus métodos de produção, a racionalizar a estocagem dos conhecimentos, a impedir o desperdício de energia intelectual. Ela encontra seu lugar na divisão do trabalho, assim como a química e a bacteriologia. (ADORNO; HORKHEIMER, 1985, p.226)

O cânone da quantidade (promovido pela necessidade de generalizações para que algo possa ser concebido como cientifico) e, posteriormente, o pragmatismo (em que tudo deve ter uma utilidade) fizeram da filosofia uma "erudição", um conhecimento para indivíduos excêntricos que procuram na teoria explicações oriundas de divagações quase sempre entendidas como caprichos de poucos. Por isso,

existe hoje um acordo quase geral em torno da ideia de que a sociedade nada perdeu com o declínio do pensamento filosófico, pois um instrumento muito mais poderoso de conhecimento tomou seu lugar, a saber, o moderno pensamento científico. (HORKHEIMER, 2000, p.65)

Não que a filosofia seja capaz dessa neutralidade ou que incorpore a "razão autêntica e verdadeira", pois, assim como o próprio Marx definiu, a filosofia também se manifesta como ideologia. O declínio da filosofia, no entanto, é a derrota da possibilidade da consolidação do "pensamento unidimensional", entendido aqui como a capacidade de questionamento e de elaboração do pensamento de protesto.

A filosofia, em outro sentido, procura mais a compreensão da totalidade (sobretudo, por meio dos grandes filósofos) do que a ciência moderna.

Sem dúvida nenhuma, o progresso científico é um fragmento, o mais importante, do processo de intelectualização a que estamos submetidos desde milênios e relativamente ao quais algumas pessoas adotam, atualmente, posição estranhamente negativa. (WEBER, 2003, p.37)

Grande parte dos intelectuais considera o aparecimento e a consolidação da ciência moderna os elementos centrais do progresso. É como se o passado não abrigasse transformações ou mudanças significativas decorrentes de formas organizadas de superação e de modificações da realidade concreta da sociedade. Criouse um imaginário de que a ciência moderna seja a única possibilidade de "salvação dos homens" de uma vida mundana, ou de uma vida condenada a insignificâncias intercambiáveis na sociedade. Todavia, "a ciência também é uma supraestrutura, uma ideologia" (GRAMSCI, 1975, p.1457), ou seja, é um conjunto de imaginários, de racionalidades e subjetividades com correspondência na realidade concreta.

A ciência vem associada ao progresso. Este é compreendido como a superação de estados mais primitivos para os mais avançados, tanto nos aspectos quantitativos como nos qualitativos. O progresso é correspondente à noção de "melhoria", de mudança para um estágio "superior". A sensação criada é a de que antes da ciência não havia progresso. Apenas com os avanços oriundos de um domínio maior sobre a natureza é que a sociedade teria passado a se modificar. Esse imaginário é manifestação clara e direta do empreendimento do esclarecimento, movimento de tendência ideológica que procura se apresentar como potência social. Assim, "o progresso é uma ideologia, o vir-a-ser é uma filosofia" (GRAMSCI, 1975, p.1335).

A concretização da ideologia como ciência, na concepção do próprio Gramsci (1975, p.507), ocorre quando a ideologia assume a "hipótese científica de caráter educativo energético". Na sociedade contemporânea, a ciência é associada ao ensino, relação entendida como indissociável. O fato é que essa associação tem fundamento econômico imediato: o interesse da indústria da educação em vender o ensino. A ciência (embora independente em muitas situações da relação direta com o ensino) é "prejudicada" na sua formação de origem e na sua "neutralidade". A indústria do ensino apropria-se da ciência porque é também no processo de geração de novos conhecimentos que se presencia o processo de aprendizado no mais alto grau de aprendizagem.

A consolidação da indústria do ensino faz das universidades fábricas da mercadoria "conhecimento". Pesquisas efetivam-se como linhas de produção gerando o produto ensino. Toda a estrutura burocrática da universidade assemelha-se à de uma fábrica ou à de uma indústria. Mesmo nas instituições públicas, veladamente, a figura do aluno é transformada em cliente. O professor passa a ser prestador de serviço. A diferença consiste na figura 
do professor como monopolista da prática avaliativa dos alunos. A burocracia do ensino ganha corpo e transforma a universidade em "multiversidade". Dessa forma,

uma universidade que produz pesquisas ou cursos a quem é apto a pagá-los perde o senso da discriminação ética e da finalidade social de sua produção - é uma multiversidade que se vende no mercado ao primeiro comprador, sem averiguar o fim da encomenda, isso coberto pela ideologia da neutralidade do conhecimento e seu produto. (TRAGTENBERG, 2004, p.16)

Nesse processo, a sociedade passa a ser o principal "cliente". Na realidade, a sociedade torna-se o ideal do "cliente", pois sob qualquer suspeita ou ferimento da ética coletiva, a sociedade apresenta-se como "superior" ou "acima" de qualquer interesse individual. Entretanto, o fato é que essa sociedade nada mais representa do que o ideal capitalista, em que o cliente individual se potencializa no discurso do cliente coletivo, a sociedade, isenta de suspeita em qualquer condição. Não se questiona o quanto de particular há no discurso coletivo do social.

De fato, sutilmente e por meio da ideologia, a ciência se constrói na direção dos interesses da classe economicamente dominante. Essa construção dá-se lentamente, "tijolo por tijolo", sem maiores questionamentos. A ciência da "neutralidade científica" é utópica, porque toda ciência é sempre uma ciência de classe ou de grupo dominante, mesmo havendo contradições no seu interior; até mesmo porque

os alunos da rede escolar recebem também conteúdos científicos. Eis que o processo de escolarização contribui para a reprodução das condições materiais de produção, uma vez que a produção social é uma transformação material da natureza, supondo o conhecimento objetivo sob as mais variadas formas. (TRAGTENBERG, 2004, p.54)

Para esconder a influência e a força com que a ideologia está presente na ciência, vários são os cientistas e filósofos que anunciaram a neutralidade científica; muitos deles, inclusive, apresentando estudos e reflexões logicamente fundamentados. Entretanto, é importante ressaltar que mesmo a lógica tradicional se rende à apresentação formal. Nem sempre as contradições estão no nível da percepção ou do aparente, pois, se assim o fosse, não haveria contradição na ciência.

\section{Mito da neutralidade da clência e a fé fillosófica e clentífica}

Adorno e Horkheimer (1985) afirmam que o mito já é esclarecimento. Na era da quantificação, a ciência (resultado do pensamento iluminista) esconde a barbárie por meio de discursos fundamentados numa suposta neutralidade, além de mascarar interesses econômicos, estando supostamente desvinculada de tendências ideológicas ou políticas. Revestida da afirmação da neutralidade "a ciência ocupa hoje o lugar do Verbo Divino. A casta dos cientistas substitui a hierarquia eclesiástica como elemento mediador entre a palavra superior e a coletividade humana" (TRAGTENBERG, 2004, p.64).

O entendimento de Tragtenberg em relação à ciência não deixa de ser uma crítica à tendência de dogmatizar a ciência e de elevá-la comparativamente às demais formas de mitologização. Dessa forma, Tragtenberg é mais Marx e menos Weber, pelo menos nesse quesito. Assim, tal como Marx, que vê na ciência uma concepção iluminista na maior parte, Tragtenberg acredita na ciência como força progressista, potencial e esclarecedora, pois proporciona aos homens maior poder sobre a natureza, contribuindo para o direcionamento do destino dos mesmos.

Apesar disso, Tragtenberg não se ilude com ela, pois sabe da perversidade da burocracia e como ela é capaz de retirar a autonomia dos indivíduos e dos grupos organizados, aspecto pelo qual Weber está presente na crítica da ciência burocratizada. Assim, se Tragtenberg, por um lado, não concorda com o sentido de "neutralidade axiológica" presente em Weber, por outro, recusa a apologia da ciência, sobretudo, recusando o otimismo dos que "louvam a ciência - isto é, a técnica de controlar a vida baseada na ciência - como o caminho para a felicidade" (WEBER, 2003, p.177). 
A ciência, como fenômeno social, não está isenta de certa tendência à personalização. Diferente em alguns aspectos das demais atividades produtivas, o domínio técnico e de conhecimentos específicos faz do cientista um indivíduo que centraliza poder por estar dotado de metodologia para a compreensão da realidade e por concentrar técnicas que possibilitam o domínio sobre a natureza.

Apesar disso,

a importância da ciência para a humanidade não se encontra vinculada ao papel dos cientistas. Estes, na maioria das vezes, restringem-se ao papel de novos sacerdotes à procura de rebanho para ser cuidado. [Tragtenberg] sabia e procurava reafirmar constantemente que os saberes não se restringiam à ciência, que esta não ocupava uma posição superior ante os demais saberes e que tampouco teria condições de disciplinar a todos. (PASSETTI, 2001, p.106)

No entendimento de Tragtenberg, a ciência é mais uma forma de saber, que se torna dominante porque é apropriada e utilizada pelas classes dominantes, efetivando-se, além disso, como principal instrumento técnico no incremento produtivo, no processo de circulação das mercadorias, no ato de consumo e no fomento ideológico necessários para intensificar a relação produção-consumo. A neutralidade anunciada, portanto, está camuflada.

Mesmo os apontamentos de Weber em relação aos limites da ciência, não deixam de ser criticados por filósofos ainda mais radicais (no sentido de ir à raiz) em relação ao papel da ciência na contemporaneidade. Entre esses filósofos, destaca-se Mészáros:

Weber justifica sua "análise científica tipológica" a partir de sua pretensa "conveniência". Sua cientificidade só existe, porém, por definição. De fato, a aparência de "cientificidade tipológica rigorosa" surge das definições "inequivocas" e "convenientes" com que Max Weber sempre empreende a discussão dos problemas selecionados. Ele é um mestre sem rival nas definições circulares, justificando seu próprio procedimento teórico em termos de "clareza e ausência de ambiguidade" de seus "tipos ideais", e da "conveniência" que, segundo se diz, eles oferecem. Além disso, Weber nunca permite que o leitor questione o conteúdo das próprias definições nem a legitimidade e validade científica de seu método, construído sobre suposições ideologicamente convenientes e definições circulares "rigorosamente" autossustentadas. (MÉSZÁROS, 2007, p.72)

A crítica de Mészáros a Weber caracteriza-se pela sua natureza ideológica. O entendimento de "tipo ideal"1 manifesta a tentativa de absolver a ciência de qualquer interferência de ordem econômica ou pessoal. A suposta ciência neutra existe como uma representação idealizada, mesmo que conceitualmente haja uma circularidade criada pelo próprio Weber para "purificá-la". A tentativa de criar uma ciência neutra, sem influência dos interesses ou vieses que contaminem seus pressupostos de neutralidade, é tão dogmática quanto a tentativa dos sacerdotes de afirmar a existência de uma religião salvadora.

A crença dos cientistas na neutralidade científica é a mesma da dos fiéis em relação às suas religiões. A necessidade da existência de um ente superior manifesta-se com racionalidades diferentes, mas que procuram aconchegar os mesmos temores humanos. A via para essa tentativa é distinta. Os resultados podem ser diferentes, mas o que se procura, tanto em uma quanto em outra, é a consolidação de uma elite específica. Tanto a elite dos sacerdotes como a dos cientistas procura essa diferenciação no interior da sua própria classe. É importante ressaltar, também, que, apesar dessa "corrida" pelas diferenciações, ocorrem lutas ideológicas, cada qual com seus pressupostos, premissas e verdades.

\section{Clêncla como força produtiva}

Forças produtivas, na concepção marxista, são elementos capazes de transformar ou de modificar a natureza. Nem sempre uma força produtiva corresponde a um elemento material ou, necessariamente, exerce o poder de modificações que implicam a criação ou a produção de bens materiais. Os avanços da física - sobretudo, da física quântica e da nanotecnologia - são responsáveis por mudanças qualitativas de grande impacto nas novas 
tecnologias, na biologia e em boa parte das ciências. Na sociedade atual, o conhecimento instrumental é apropriado, basicamente, pelo capital. Da tecnologia da informação, passando pela engenharia genética, até os treinamentos gerenciais que transmitem as "competências gerenciais", cria-se uma economia do conhecimento "imaterial" (GORZ, 2005), cujo valor gerado é apropriado pelo capital. Apesar disso, a dialética da produção da vida impede que o "capital fixo material" seja completamente substituído pelo "capital humano", pelo "capital do conhecimento" ou pelo "capital da inteligência".

Geralmente, as forças produtivas estão associadas aos meios de produção, materiais ou não. Entretanto, a ciência pode ser considerada força produtiva? Ou é uma mercadoria? A ciência como instrumento de modificações da natureza e do domínio sobre ela deve ser entendida como força produtiva. No entanto, quando se apresenta como resultado de trabalho realizado (ou trabalho vivo), equivalente a uma propriedade privada, a ciência torna-se mercadoria.

A ciência despida da sua suposta neutralidade axiológica constitui instrumento de dominação e manifestação do resultado do trabalho socialmente despendido. Todavia, é importante ressaltar que não há uma ciência, mas várias. A ciência é resultado das relações sociais de produção e manifesta-se como elemento impossível de ser separado das atividades humanas ocorridas no trabalho. Principalmente, porque, no atual momento de desenvolvimento das forças produtivas, não é mais factível a separação do que é ciência do que é ideologia.

A dita neutralidade científica é consequência da necessidade de esconder a quem realmente a ciência serve, tanto na sua forma de força produtiva como na de mercadoria. Se o passado procura isentar a tentativa de Weber em relação à neutralidade da ciência, o presente cria a necessidade de desconfiar de todas as tentativas de "purificação" existentes. Assim, como Kant afirma, não é possível pensar sem as operações dos conceitos, pois, mesmo o mais simples pensamento não se isenta dessa necessidade. Da mesma forma, os conceitos não implicam total isenção de valores, pois resultam das relações sociais, neles estando presentes pelo menos duas figuras: quem conceitua e quem opera os conceitos.

Por essa perspectiva, todas as derivações da ciência e da produção de conhecimento estão dentro do princípio da ciência, seja como forças produtivas ou como mercadoria. Os discursos derivados dessa lógica (inovação tecnológica, desenvolvimento sustentável e demais) são, na realidade, discursos para o controle do capital. De tal modo, "a inovação tecnológica e a pesquisa científica confluem para um estuário: a acumulação da maisvalia relativa e a reprodução ampliada do capital" (TRAGTENBERG, 1974, p.216).

A subordinação da ciência ao capital é uma realidade. Se não ao capital privado, pelo menos, ao capital estatal. Eis que a ciência não se isenta nem mesmo da formação das elites da burocracia estatal. Em regime de capital planificado, a ciência cria a própria metodologia e procedimentos para enquadrar as regras definidas externamente a ela. Manifestação disso é a existência de uma ciência exclusiva para o controle do capital sobre a ciência: as ciências contábeis.

Mesmo referente às ciências tidas como as mais técnicas e pragmáticas possíveis, sua criação é sempre um fenômeno social, sujeita à reprodução sociometabólica do capital (MÉSZÁROS, 2001). A contradição é que, mesmo

o fato de a ciência ser força produtiva e meio de produção que coopera para o processo de vida da sociedade, não justifica, de forma alguma, uma teoria pragmática do conhecimento. [...] Sem dúvida, a própria ciência se modifica no processo histórico, mas a referência a isso nunca pode valer como argumento para a aplicação de outros critérios de verdade que não aqueles que correspondem ao nível de conhecimento no grau de desenvolvimento alcançado. (HORKHEIMER, 1990, p.7)

O pragmatismo da ciência é consequência do seu atual desenvolvimento como força produtiva ou do seu resultado como mercadoria de pertencimento privado. Não é estranho, portanto, que

o conhecimento aparece como força produtiva, a produção se dá como objetivação do conhecimento, a produção e reprodução da vida social dependem da inteligência coletiva, o tempo livre se torna 
medida da riqueza e não mais o tempo de trabalho; este adquire aspecto lúdico. (TRAGTENBERG, 1974, p.214)

O conhecimento científico, nos seus diversos níveis e formatações, está presente nas relações entre os indivíduos. Seja como produtores ou como consumidores, diretos ou indiretos, desse conhecimento, o fato é que a razão científica está presente na organização da sociedade, na forma como ela se reproduz, no fomento para uma sociedade que domine a natureza para sua utilidade. A razão por trás desse conhecimento é o direcionador da forma como os indivíduos devem interpretar grande parte do mundo e das relações que o cercam. Por exemplo:

É fácil identificar o lugar da ciência na divisão social do trabalho. Ela tem por função estocar fatos e conexões funcionais de fatos nas maiores quantidades possíveis. A ordem do armazenamento deve ser clara. Ela deve possibilitar às diversas indústrias descobrir prontamente a mercadoria intelectual desejada, na especificação desejada. Em larga medida, a compilação já é feita em vista de encomendas industriais precisas. (ADORNO; HORKHEIMER, 1985, p.226)

O conhecimento científico não tem preferências, mas está sob orientação da produção em escala industrial. As amarras da ciência, como produtora de conhecimento específico enquadrado em procedimentos e formatações possíveis de serem vendidas, fazem dela um processo de produção e não um fim em si mesmo, em que os indivíduos são beneficiários do continuo processo de dominação da natureza por parte da razão científica. Em outros tempos, mais especificamente nos anos 1940 e 1950, Horkheimer afirmou que a ciência estava em crise:

Por mais que se fale com razão de uma crise da ciência, ela não pode separar-se da crise geral. $O$ processo histórico trouxe consigo um aprisionamento da ciência como força produtiva, que atua em suas partes, conforme seu conteúdo e forma, sua matéria e método. Além disso, a ciência como meio de produção não está sendo devidamente aplicada. A compreensão da crise da ciência depende da teoria correta sobre a situação social atual, pois a ciência como função social reflete no presente as contradições da sociedade. (HORKHEIMER, 1990, p.12)

A sugerida existência de uma crise é de ordem ética, mais especificamente, de uma ética coletiva, pois sob a ótica da ética do capital, em que a moral é o lucro, a ciência jamais passou por momentos de crise. De certa forma, em grande parte é a ciência que garante a contínua reprodução do capital, por meio das técnicas desenvolvidas, dos sistemas criados e da tecnologia da informação. Sem os avanços da ciência, portanto, a reprodução sociometabólica poderia gerar uma crise de fato. $\mathrm{Na}$ atualidade, a sociedade detém suficiente conhecimento científico para garantir tanto a produção com mais qualidade e controle como, também, técnicas de vendas para aperfeiçoar a compra das mercadorias geradas pelo próprio sistema produtivo de base científica.

A crise, portanto, atinge aqueles que entendem que a ciência tem de estar a serviço da maioria; não, de uma minoria. Nunca a ciência foi tão importante para a reprodução do sistema capitalista; nunca se investiu tanto para a geração de novas técnicas, novos procedimentos, novos sistemas produtivos como na atualidade. Se não fosse em grande parte a contribuição dos cientistas, a crise causada pela falta de controle (pelo desencontro) do capital como força destrutiva seria muito mais evidente e problemática.

A ciência, nas suas variadas formas e concepções, é um produto histórico. Em cada época, vem para atender aos interesses dos grupos dominantes, mas, ao mesmo tempo, atende a outros grupos, porque a própria ciência precisa se apresentar como fonte mediadora dos conflitos e dos diversos grupos que compõem a sociedade. Por isso, "ainda que a ciência esteja compreendida na dinâmica histórica, ela não deve ser destituída do seu caráter próprio e utilitariamente mal interpretada. [...] a ciência é um fator do processo histórico" (HORKHEIMER, 1990, p.7-8). Persiste a esperança.

Como processo histórico, as descobertas científicas e o conhecimento gerado por ela são utilizados de diversas formas. A ciência tanto pode ser um instrumento para o "bem" quanto para o "mal". Todavia, o capital que orienta grande parte da produção científica se tornou o principal instrumento de repressão ou de sublimação da atual sociedade. Assim, a ciência serve, também, tanto para libertar os homens como para aprisioná-los. Apesar 
das duplas possibilidades, não é possível negar que o capitalismo seja um sistema econômico bastante confluente com o lado "sombrio dos homens", com a perversidade coletiva e com a pulsão de morte.

\section{"Matar e morrer" com as armas da clêncla: o complexo Industrial militar como financlador da destrulção}

O capital se apropria de todas as forças produtivas, desenvolvendo-as de acordo com seu interesse, inclusive, em relação à ciência. Dessa forma, uma parte da ciência é estranha ao operário da produção e, até mesmo, aos indivíduos que trabalham para a manutenção e o controle do capital. A outra parte é incorporada pelos operários como ideologia, conforme o próprio Maurício Tragtenberg afirma: a teoria geral da administração é ideologia. Nas escolas de administração, os alunos dos primeiros períodos a concebem na aprendizagem como ciência. Isto porque a literatura que aborda a temática apresenta a história da administração e as escolas componentes de forma funcionalizada e pragmática, ou seja, como conhecimento instrumental de base para as disciplinas específicas de natureza técnica, tais como administração da produção, de recursos humanos, financeira e demais. É por isso que a ciência é contraditória, pois, ao mesmo tempo em que liberta, aprisiona. Assim, a ciência pode ser considerada um instrumento de opressão de uma classe ao mesmo tempo em que é um instrumento de dominação de outra. A ciência não pode ser definida como uma categoria moral, mas tem sua dimensão política e ideológica.

Não é a ciência (e os conhecimentos gerados por ela) que destrói. É sua utilização política em favor de determinadas classes para exercer opressão sobre outras. A bomba nuclear, as armas químicas, as armas de fogo e todos os "produtos" resultantes dos conhecimentos científicos aplicados não podem ser responsabilizados pelas matanças ou genocídios praticados na história da humanidade. Uma simples faca de cozinha também pode matar. A questão também não é responsabilizar o indivíduo isolado, pois, apesar da sua parcela de responsabilidade em razão de seu livre-arbítrio, a formação do seu Ser é resultado das relações sociais.

A correta utilização da ciência torna-se cada vez mais clara, à medida que se desmistifica a própria ciência. A substituição dos mitos antigos pelo mito da ciência como "salvador dos indivíduos" contém o mesmo gérmen da dominação e da diferenciação entre classes. A contemporaneidade apenas consolida no tempo presente a ideia de Habermas (1997, p.98-99):

Hoje, no sistema de trabalho das sociedades industriais, os processos de investigação combinam-se com a transformação técnica e com a utilização econômica, e a ciência vincula-se com a produção e a administração: a aplicação da ciência na forma de técnica e a retroaplicação dos progressos técnicos na investigação transformaram-se na substância do mundo do trabalho. (HABERMAS, 1997, p.98-99)

Se em outros tempos a religião era o grande instrumento ideológico, na atualidade, a ciência apresenta-se como a ideologia materializada no interior das relações econômicas e sociais. As relações econômicas na Idade Média configuravam-se diferentemente da forma como ocorrem hoje. A função da religião como instrumento de controle ideológico era o meio mais compatível com o grau de desenvolvimento econômico da época. $\mathrm{Na}$ atualidade, o mito está também presente no discurso de salvação pela ciência.

O grau de desenvolvimento econômico de uma determinada época (mais especificamente, o relacionado ao desenvolvimento das condições materiais de existência de uma sociedade) é o elemento que cria e consolida técnicas responsáveis pelo domínio crescente dos homens sobre a natureza.

Esse domínio, inevitavelmente, também recai naquele que o homem exerce sobre si próprio. Se antes a dominação era exercida pelo poder de violência e de coerção, hoje, o capitalismo traz outras formas até mais "requintadas" de dominação; muitas, inclusive, de natureza psíquica. Todavia, o requinte e a mudança da natureza da dominação não levam, necessariamente, à ausência de alguma forma de violência. $\mathrm{O}$ poder de destruição persiste e potencializa-se, porquanto o que antes estava centrado na ação dos sujeitos (soldados, policiais, fundamentalistas e outros), hoje, está disseminado no conhecimento ou nas técnicas utilizadas nas formas de gestão, nos produtos gerados pela ciência e nos mecanismos de controle psicológico encomendados e 
produzidos pela psicologia. Há evidente concentração das grandes violências, o que não impede que as de menores consequências devam ser negligenciadas ou mesmo desconsideradas.

A concentração de poder de destruição ainda está, inevitavelmente, no complexo militar industrial. Por isso,

nos países capitalistas avançados, todos os ramos da ciência e da tecnologia são levados a funcionar em auxílio aos objetivos das poderosas estruturas econômicas e político-organizacionais. As linhas tradicionais de demarcação entre "ciência pura" e "ciência aplicada" - assim como entre os negócios e o universo cada vez mais desdenhado da "academia" - são radicalmente retraçadas para adequar todas as formas de produção intelectual às necessidades do complexo militar-industrial. (MÉSZÁROS, 2007, p.287)

\section{Processo de racionalização da clêncla: o pragmatismo e a burocracla universitária}

Habermas (1982) opõe-se ao cientificismo positivista de Karl Popper, Carl Hempel e Paul Oppenheim, ao pretenderem definir os critérios de "toda verdade científica". Habermas faz uma reconstrução histórica defendendo a particularidade das ciências sociais. A tese defendida pelo frankfurtiano é a de que há um vínculo entre conhecimento (ciência) e interesse (no sentido do interesse universal). As ciências consideradas exatas são orientadas por procedimentos empírico-analíticos, que não podem ser generalizados ou adotados como procedimento para as ciências sociais.

A discussão do domínio das ciências pragmáticas e a forma como suas características e pressupostos são incorporados pelas ciências sociais não é uma preocupação somente de Habermas. Vários outros intelectuais entre eles Adorno, Bourdieu, Touraine e Tragtenberg - alertaram para a tendência totalitária de transformar as ciências sociais em uma extensão das ciências pragmáticas.

A influência das ciências experimentais ou racionalistas, baseadas em cálculos e modelos de natureza matemática, está presente em grande parte das formas de saber. Nem mesmo a filosofia escapa a essa regra, conforme afirma Horkheimer (2000, p.51):

Como a ciência, a própria filosofia tornou-se não um exame contemplativo da existência nem uma análise do que se passou e foi feito, mas uma visão das possibilidades futuras com a indicação de que se alcance o melhor e se evite o pior. Probabilidade, ou melhor, o cálculo, substitui a verdade, e o processo histórico que na sociedade tende a tornar a verdade uma expressão vazia recebe as bênçãos do pragmatismo, que transforma isso numa expressão vazia dentro da filosofia.

O pragmatismo incorporado pela ciência, aliado à influência do capital na constituição de redes de criação de conhecimento para produção de produtos passíveis de serem comercializados, fomenta investimentos específicos em determinados projetos científicos. Exemplo disso são os investimentos na tecnologia de guerra, na ciência do espaço, na engenharia genética, na nanotecnologia ou na física quântica aplicada.

Todavia,

tentar transformar a física experimental num protótipo de todas as ciências e modelar todas as esferas da vida intelectual segundo as técnicas do laboratório, pragmatismo torna-se o correlato do industrialismo moderno, para quem a fábrica é o protótipo da existência humana, e que modela todos os ramos da cultura segundo a produção na linha de montagem ou segundo o escritório racionalizado. (HORKHEIMER, 2000, p.57)

O pragmatismo divide a realidade em "mundo prático" e em conhecimento teórico, potencializando a compreensão da realidade em frações e fronteiras científicas. Assim,

o chamado mundo prático não tem lugar para a verdade, e, portanto, divide-a em frações para conformá-la à sua própria imagem: as ciências físicas são dotadas da chamada objetividade, mas 
esvaziadas de conteúdo humano; as humanidades preservam o conteúdo humano, mas só enquanto ideologia, a expensas da verdade. (HORKHEIMER, 2000, p.81)

Tais fronteiras do conhecimento são erguidas e delimitam as teorias e procedimentos. Entretanto, os limites ocorrem em relação ao emprego e à utilização do método, não em relação à sua utilização. Exemplo disso é

a emergência da Revolução Industrial, [que] implica uma alteração das condições de produção, substituição da manufatura pela fábrica, absorção do êxodo rural na nova mão de obra industrial, transferência de capitais do campo à cidade e aproveitamento dos resultados das Ciências Naturais do universo industrial. (TRAGTENBERG, 1974, p.58)

Nessa época, o darwinismo surgia como uma ideologia conservadora, na medida em que atribuía à natureza a origem da luta geral pelo sucesso econômico, estabelecendo uma confusão entre sobrevivência - que depende de outros fatores além de habilidade e capacidade individuais - e desenvolvimento biológico. Confundia conformidade com melhoria e adaptação com superioridade física. A teoria da seleção natural consagrava o processo de expansão do capitalismo, dando novo impulso ao imperialismo. Pouco importava saber que um dos sustentáculos da vida dentro das espécies é mais a cooperação do que a luta. Não fora como biólogo, mas como criador de mitos, que Darwin se impusera. As necessidades de afirmação brutal, da classe, nação e raça dominantes, segundo um dogma "científico". ${ }^{2} \mathrm{O}$ conhecimento gerado pela observação da dinâmica do reino animal é transportado para a "selva" da dinâmica da economia.

Esse é apenas um dos vários exemplos da influência de conhecimentos específicos importados na tentativa de explicar uma realidade originada em condições diferentes. Em grande parte, isso ocorre não apenas devido à crescente especialização, mas também à formação de teorias com linguagens de identificação imediata. A forte presença da ciência positiva, do funcionalismo e do pragmatismo faz com que as teorias construídas com base em seus pressupostos possam ser facilmente interpretadas pelos diversos ramos do conhecimento. Weber já havia anunciado essa tendência em relação à especialização:

Atualmente e naquilo que se refere à organização científica, essa vocação é determinada, antes de mais nada, pelo fato de que a ciência atingiu um patamar de especialização que ela não conhecia nos velhos tempos e no qual, segundo podemos julgar, se manterá ao longo do tempo. Essa afirmação tem sentido em relação às disposições interiores do próprio cientista, tendo em vista que jamais um indivíduo poderá ter certeza de alcançar qualquer coisa de valor real no domínio da ciência, sem possuir uma rigorosa especialização. (WEBER, 2003, p.32)

As ciências sociais também são influenciadas pela tendência à especialização. Toda estrutura criada para atender à ciência "sociologia" está alicerçada na organização das condições materiais que atendem aos interesses do capital. A especialização da sociologia, portanto, é a mesma especialização necessária para a ampliação do capital e para a dominação intelectual do grupo dominante. É por isso que

o saber sociológico atualmente não é simplesmente um aspecto da cultura universitária; tornou-se elemento de poder, daí a proliferação de centros de documentação, bancos de dados, institutos de planejamento: a escolha das pesquisas depende dos financiamentos possíveis; por outro lado, a "moda" acadêmica impõe sua tirania. Uma pesquisa é determinada não porque se é obrigado a ter esta ou aquela orientação teórica para receber financiamento, mas recebe financiamento por esta ou aquela orientação teórica; trata-se de uma determinação que opera com alto nível de sutileza. (TRAGTENBERG, 2004, p.24)

Tragtenberg (2004, p.25-27) afirma ainda que as universidades americanas estão a serviço do capital, inclusive, as frentes de ciências responsáveis por colocar em risco a própria condição de segurança da humanidade. Todo programa nuclear foi desenvolvido em universidades e institutos de tecnologia americanos. A Guerra Fria, dessa forma, foi nutrida pela ciência dessas instituições. Os princípios da energia nuclear e o projeto Manhattan (de desenvolvimento da bomba atômica) foram criados pelos cientistas da física. Aos sociólogos americanos coube a missão de criar uma "engenharia do consenso", necessária para justificar a utilização da bomba atômica contra as cidades de Hiroshima e Nagasaki. Dessa forma, 
o grave problema da universidade norte-americana atual é a síndrome de conformismo, que permite a utilização do saber para o genocídio, para prevenir conflitos futuros, tornando o sociólogo um burocrata auxiliar e triste do Departamento de Defesa. (TRAGTENBERG, 2004, p.30)

A ciência social, nesses casos, não é para servir à sociedade, constituindo-se mais como ciência da dominação voltada para a destruição. Filosofia e sociologia são "fábricas" de racionalidades que justificam e formam o consenso para a barbárie. A destrutividade humana ganha aliados importantes, supostas razões que justificam os regimes do medo, extermínios, pânico e desespero humano. É por isso que

a era da sociologia "inocente" terminou, surgindo a era da sociologia militante, a serviço dos profetas armados. De igual forma, agem os sociólogos da indústria que aceitam a ideologia do "gerencialismo", uma ideologia patronal para manipular os dominados. A automatização dos campos de batalha futuros é elaborada no campus. (TRAGTENBERG, 2004, p.25 e 26)

Os "campos de batalhas" estão justificados e recebem apoio dos indivíduos adeptos do senso comum revestido de conhecimentos supostamente científicos. A indústria da espetacularização da mídia de massa torna-se o disseminador da razão profética e amenizadora das culpas sociais. Uma legião inteira de sociólogos e filósofos cria discursos comuns capazes de fomentar um imaginário de supremacia da razão como condutor do destino social. Ciência e barbárie, neste momento, são faces contrárias de uma mesma moeda.

O preço pago pelos marginalizados e pelos sujeitos diretamente envolvidos nos conflitos são mostrados nos programas televisivos, relatados nos jornais e ditos nos programas de rádios sem que o peso do sofrimento esteja associado à descrição das informações. Grande parte da sociedade comove-se, mas permanece alheia aos sentimentos que a barbárie pode causar nas vítimas das violências.

As universidades americanas atendem a esse complexo econômico militar, um dos alicerces da economia norteamericana. A indústria militar é geradora de inovações, em grande parte, incorporadas na inovação de produtos de uso geral, consumidos por cidadãos comuns. Nesse sentido,

a criação do conhecimento e sua reprodução cedem lugar ao controle burocrático de sua produção como suprema virtude, em que "administrar" aparece como sinônimo de vigiar e punir - o professor é controlado mediante critérios visiveis e invisíveis de nomeação; o aluno, mediante critérios visíveis e invisiveis de exame. Isso resulta em escolas que se constituem depósitos de alunos, como diria Lima Barreto, em Cemitérios de vivos. (TRAGTENBERG, 2004, p.18)

As formas de controle burocrático são institucionalizadas pela política geral dos órgãos responsáveis por regular a educação e a política de tecnologia e ciência de cada país. As demais instituições, indiretamente, são responsáveis por criarem as políticas necessárias para a afirmação da ideologia dominante. No interior dessas universidades, os burocratas, muitos deles transformados em professores e cientistas, são responsáveis por defender as regras instituídas pelas políticas de ensino e de tecnologia e ciência. O interesse é imediato e direto: a perpetuação desses mesmos burocratas no poder. Regras internas, expressas nos documentos obrigatórios para formalizar a adequação da Universidade aos princípios capitalistas, são "impostas" com discursos docilizados de democracia universitária.

Weber já havia anunciado essa preocupação no que diz respeito ao sistema alemão de ensino:

Ultimamente, podemos observar nitidamente que, em numerosos domínios da ciência, desenvolvimentos recentes do sistema universitário alemão orientam-se em conformidade com padrões do sistema norte-americano. Os grandes institutos de ciência e de medicina se transformaram em empresas de "capitalismo estatal". É impossivel administrar essas empresas sem dispor de recursos financeiros consideráveis. É notável o surgimento, como, aliás, em todos os lugares em que se implanta uma empresa capitalista, do fenômeno específico do capitalismo, que é o de "privar o trabalhador dos meios de produção". (WEBER, 2003, p.27)

O Estado controla suas instituições universitárias pelo orçamento. Agências de fomento à pesquisa e à ciência fixam seus editais de forma a "orientar" as verbas e os recursos financeiros para áreas de interesse das elites 
econômicas dominantes. A subordinação é clara e direta. As regras para receber o fomento variam de acordo com os interesses da economia. Poucas bolsas de estudos ou recursos são destinados a pesquisas que não privilegiem o interesse do capital. A existência delas é meramente ilustrativa e com a finalidade de "anunciar" a ilusória democracia do conhecimento. Os malefícios da burocracia do ensino e da ciência, somados à rede privada, potencializam a indiferença real com o cientista, transformando-o em mero instrumento de meio, pouco relacionado com os fins da ciência. $\mathrm{O}$ cientista torna-se um trabalhador da ciência que não dispõe, na realidade estatal,

de recursos que não os instrumentos de trabalho que o Estado põe ao seu alcance. Nesse sentido, ele depende de seu patrão - já que o diretor de um instituto pensa, com total boa-fé, que aquele é seu instituto. Daí passa a dirigi-lo a seu bel-prazer, de modo que a posição do assistente, nesses institutos, é, normalmente, tão precária quanto à de qualquer outra existência 'proletaroide', ou até quanto à dos assistentes das universidades norte-americanas. (WEBER, 2003, p.27-28)

Mesmo os cursos de pós-graduação, responsáveis pela formação de cientistas e pesquisadores, não ficam fora dessa regra. Conforme Tragtenberg (2004, p.80) afirma,

o curso de pós fica reduzido a ser pós-de-coisa-alguma. ${ }^{3}$ A universidade, controlada em sua função pedagógica pela burocracia, por ter sua função de pesquisa redefinida fora de seu meio, por agências de financiamento nacionais e internacionais, é "domesticada". Reduz-se à criação de mão-de-obra "superior" requerida pelo sistema, sem mais nada, sem fantasia.

De fato, não ocorre a suposta neutralidade axiológica, pois as ideologias estão o tempo todo permeando o espaço, os procedimentos e os recursos financeiros do pesquisador. Sua subordinação à burocracia científica limita-o na sua jornada pela busca do conhecimento científico. É nesse sentido que a pós-graduação se tornou, segundo o próprio Tragtenberg (1974), o "bode expiatório" da ciência.

Conforme Uhle (2001, p.153) afirma,

Há crimes lógicos e passionais; a distância que os separa é incerta, são definidos os primeiros pela existência da premeditação. Da mesma forma que a existência do carrasco pressupõe a vítima, o poder monocrático e vertical implica bodes expiatórios. Essa é a função da pós-graduação nos discursos do Poder, através de seus representantes mais autorizados. Justamente numa época em que cursos de pós-graduação difundiram-se pelo território nacional, e nesse sentido democratizaram-se, são taxados de elitistas e como tais voltados à extinção decretada pelos donos do poder.

O suposto poder da elite intelectual é reduzido à burocracia estatal direta ou indireta, presente tanto nas instituições públicas quanto nas privadas. A abertura de vagas na pós-graduação sofre dupla contradição:

é alvo de reserva quanto à possibilidade de abertura de novas vagas, denotando certo movimento para reservar o mercado para os cientistas e pesquisadores já atuantes; e

é defendida para consolidar a "democracia" e a universalização do conhecimento.

A burocracia apresenta as contradições do sistema no seu interior. Assim, é necessária a "produção do conhecimento e, para isso, [é imprescindível apostar] na liberdade do pesquisador para buscar problemas socialmente relevantes para seus estudos. Por essa crença na necessidade de autonomia de pesquisadores e instituições de pesquisa é que [Tragtenberg] criticou sempre os acordos de interesse, os grandes financiamentos que fecham a agenda do pesquisador, os célebres convênios com as empresas privadas ou com as fundações Ford, Rockfeller e tantas outras. Daí porque sua história mostra o currículo de um intelectual que nunca teve uma bolsa de estudos, nunca fez um estágio internacional, mas nem por isso deixou de ser cosmopolita" (UHLE, 2001, p.165).

O processo de racionalização no ensino e na ciência não é um evento à parte. É parental com o mesmo fenômeno ocorrido nos processos de trabalho. A especialização extrema aliena o cientista do fato gerador do conhecimento. O controle financeiro subordina a pesquisa aos interesses econômicos. As normas, regras e 
procedimentos engessam a ação do cientista e do pesquisador. Para aceitar essas condições sem maiores "traumas" ou sofrimentos, cientistas e pesquisadores aceitam as regras impostas pelas fontes financiadoras. As universidades nada mais são do que grandes organizações burocráticas, organizadas de forma a garantir a reprodução das suas elites internas. O processo de racionalização das universidades está em concordância com o processo já definido por Weber como "desencantamento do mundo", pelo qual o próprio conceito weberiano de neutralidade axiológica perde sentido. Porquanto não é possível neutralidade em um processo cuja forma mais comum de racionalização não seja um fim em si mesmo, mas tão somente um meio para a realização das elites orientadas e motivadas para o acúmulo permanente de capital, nem que seja por meio de uma economia militar orientada mais para a destruição do que para a melhoria da sociedade.

\section{(Sem) saber e (com) poder: Francis Bacon e o mito do "o conhecimento é em si mesmo um poder" - por uma breve conclusão?}

Francis Bacon é considerado o precursor do racionalismo. A ruptura com a tradição filosófica anterior possibilitou o surgimento de uma nova filosofia. $\mathrm{O}$ aparecimento do pensamento imanentista (a construção da filosofia por meio da razão, ao invés de admitir a prevalência do real) é responsável por focar o indivíduo do saber como detentor do poder: "a ciência e poder do homem coincidem, uma vez que, sendo a causa ignorada, frustra-se o efeito. Pois, a natureza, não se vence, se não, quando se lhe obedece” (BACON, 1988, p.13).

Bacon, na época em que fez suas reflexões, conseguiu imaginar em que medida a ciência, como força transformadora da realidade, iria se desenvolver. Mais do que isso, imaginou a força destrutiva, por meio do complexo industrial militar, como orientadora da ciência e de grande parte das pesquisas aplicadas. Conforme afirma Passetti (2001, p.108),

em "O saber e o poder" [Tragtenberg], localiza as orientações de Bacon como investimento, num saber que se disponibiliza de maneira serviçal à dominação. Seu foco atinge em especial as conexões cientificas com o colonialismo e as guerras, mostrando como os intelectuais se transformam em "parte integrante do complexo militar-industrial-acadêmico", orientado pela especialização e criação de modas universitárias que se impõem pela tirania. Receber financiamento implica ajustar-se às teorias definidas pelas agências, num complexo desenho de engenharia social: "na medida em que os cientistas propõem terapia de controle sobre os que estão abaixo, eles servem aos que estão acima”.

A realidade de Bacon era diferente da atual. A passagem da filosofia para a ciência ocorreu e sedimenta-se na noção de materialidade da ideologia. A filosofia, a sociologia e todas as ciências humanas apresentam-se como produtoras de racionalidades que justificam a utilização da ciência como meio de dominação, não só da natureza como também dos próprios homens. Essas racionalidades e imaginários vêm amparados pela ideia de que a ciência é neutra. Uma mitificação ocorre por conta disso e cria uma "fé" na filosofia e na ciência, como libertadora dos homens em relação a todas as formas de sofrimento e angústias existenciais.

Nessa relação de fé há um equívoco de concepção. A ciência é, na atualidade, uma força produtiva ou uma mercadoria. Constitui força produtiva quando transforma materialmente a realidade ou quando serve para promover e intensificar o acúmulo do capital, seja por meio da exploração crescente da mais-valia absoluta ou pela intensificação da mais-valia relativa. Constitui mercadoria quando apropriada por indivíduos ou grupos dominantes que monopolizam sua utilização ou quando exercem as propriedades fetichistas tal como Marx abordou e, ainda, mercadoria quando de fato é apenas a extensão da propriedade privada. A ciência, seja ela força produtiva ou mercadoria, é fator importante nas relações de produção existentes.

Além disso, a ciência pode ser força produtiva de destruição. A humanidade vivencia uma relação entre "matar e morrer" gerada pelas armas que a ciência disponibiliza por meio de um complexo industrial militar cada vez mais crescente. A ciência, como força produtiva dessa natureza torna-se, na realidade, financiadora da destruição. Nessas circunstâncias, inexiste a neutralidade da ciência porque a ideologia atua com força material ou como formadora do imaginário da dominação. 
A forma mais perversa de sedimentação da ciência como força produtiva destrutiva consolida-se, em grande parte, nas racionalizações que geram o pragmatismo ou a universidade burocrática. Essa burocracia é construída para a manutenção dos privilégios da elite intelectual que a ocupa. A universidade como local de produção da ciência apresenta-se como a consolidação dos interesses do capital, uma vez que aprisiona e transforma a maior parte da produção científica em mercadoria ou força produtiva.

Pelas contradições que a sociedade capitalista apresenta é possível viver sem saber e com poder, pois no capitalismo, o que confere poder nem sempre é o domínio do saber científico. Da mesma forma, o inverso pode ser verdadeiro: com saber e sem poder, o primeiro como consequência e o segundo como resultado. Assim, a afirmação dogmática de que saber é poder não passa, em algumas situações, de um mito presente na sociedade. O poder, conferido por determinados conhecimentos, ganha força e importância de acordo com os interesses defendidos ou o grupo dominante.

Algumas reflexões precisam ser feitas com base em afirmações de Tragtenberg:

quando passaremos a nos preocupar de fato "com as finalidades sociais do conhecimento", evitando, assim, "a 'delinquência acadêmica' ou a 'traição do intelectual'?" (TRAGTENBERG, 2004, p.16);

uma nova organização do trabalho, diferente da existente no modo de produção capitalista, é suficiente para "elevar" a ciência a uma nova ética centrada nos interesses dos indivíduos e seus coletivos, ao invés dos interesses das elites dominantes?

Nem toda pesquisa ou reflexão precisa acabar com certezas ou afirmações. A grande propriedade do saber, incluindo a ciência em todas as épocas, é a capacidade de elaborar suas questões, de levantar as problemáticas que permeiam a sociedade, de questionar a própria razão vigente, embora, nem sempre, chegue a respostas definitivas. Dessa forma, quais questões o leitor pode criar após esta leitura? 


\section{Referênclas}

ADORNO, Theodor W; HORKHEIMER, Max. Dialética do esclarecimento. Rio de Janeiro: Jorge Zahar Editores, 1985.

BACON, Francis. Novum organum. São Paulo: Nova Cultural, 1988. (Coleção Os Pensadores).

GORZ, André. O imaterial. São Paulo: Annablume, 2005.

GRAMSCI, Antonio. The formation of intellectuals. London: Lawrence and Wishart, 1975.

HABERMAS, Jürgen. Conhecimento e interesse. Rio de Janeiro: Zahar, 1982.

Técnica e ciência como "ideologia". Lisboa: Edições 70, 1997.

HORKHEIMER, Max. Teoría crítica I-Max Horkheimer. São Paulo: Perspectiva; Editora da USP, 1990.

Eclipse da razão. São Paulo: Centauro, 2000.

MÉSZÁROS, István. O poder da ideologia. São Paulo: Boitempo, 2001.

O desafio e o fardo do tempo histórico. São Paulo: Boitempo, 2007.

PASSETTI, Edson. Maurício Tragtenberg, um socialista heterodoxo. In: ACCIOLY; SILVA, Doris; MARRACH, Sonia Alem. Maurício Tragtenberg: uma vida para as ciências humanas. São Paulo: Editora Unesp, 2001.

TRAGTENBERG, Maurício. Burocracia e ideologia. São Paulo: Ática 1974.

A nova eugenia. Folha de São Paulo, p. 6, 23 dez. 1984.

Sobre educação, política e sindicalismo. São Paulo: Editora Unesp, 2004.

UHLE, Agueda Bernardete Bittencourt . Tragtenberg e a educação. In: ACCIOLY; SILVA, Doris; MARRACH, Sonia Alem. Maurício Tragtenberg: uma vida para as ciências humanas. São Paulo: Editora Unesp, 2001.

WEBER, Max. Ciência e política: duas vocações. São Paulo: Martin Claret, 2003.

${ }^{1}$ O tipo ideal weberiano é um instrumento de análise sociológica para a compreensão da realidade social. É um mecanismo de criação de tipologias puras, supostamente destituídas de "valores avaliativos". Seu distanciamento da realidade é tido como fundamental para a sua compreensão.

${ }^{2}$ Tragtenberg (1984).

3 "Na realidade, o que os subdesenvolvidos aprendem a respeitar na ideia de ciência são os conceitos abstratos, as realizações experimentais que não podem ser reproduzidas por eles e que não têm relação com sua cultura. Ficam em estado de impotência intelectual em relação à Metrópole, que capta os melhores estudantes para o doutorado, na sua maioria, oriundos da América Latina". (TRAGTENBERG, 2004, p.33) 